\title{
Perceptions of Treatment Value, Therapeutic Orientation, and Actual Experience of Psychiatric Residents
}

\author{
Jorge I. Casariego and John F. Greden
}

A

LTHOUGH A FAIRLY EXTENSIVE literature exists on how psychiatrists develop professionally, ${ }^{1-9}$ three important areas remain inadequately documented. First, doubts remain about the ideologic orientation of residents toward psychiatry. Second, how psychiatry residents perceive the value of various treatment modalities used in psychiatry is essentially undetermined. Third, the actual experience that residents accumulate in using various treatment modalities requires considerable elaboration. These deficiences of information are striking since a psychiatrist's professional identity is clearly related to what he believes valuable and what experiences he incorporates in his practice. ${ }^{10}$ The investigators that have evaluated these three topics have concentrated on the attitudes toward treatment approaches mainly of practicing psychiatrists, ${ }^{11-15}$ although the work by Stone and his colleagues is a major exception. ${ }^{16}$

In this era of concern about the question "what is a psychiatrist?" (as shown by the existence of an American Psychiatric Association Committee to study this subject), renewed attention must be given to the possible danger of premature theoretic closure among psychiatry residents. If ideologic closure occurs early in residency, the acquisition of new knowledge will clearly be impaired.

The present study evolved from our observations that residents in several residency programs in the Washington, D.C./Baltimore, Md. vicinity seemed to share the same opinions about the worth of various therapies regardless of level of training and orientation of their programs. Most residents also seemed to be firmly set in their opinions at an early stage. To provide some data for these subjective impressions, we decided to survey a relatively large population of psychiatry residents. Several main questions were formulated:

How do residents from different training programs rate the value of various psychiatric treatments when applied to three hypothetic psychiatric conditions?

Do residents in different levels of training rate treatment modalities differently?

What is the self-reported treatment orientation among the population of psychiatry residents?

Does premature ideologic closure appear to be present?

\section{MATERIALS AND METHODS}

The questionnaire used in the survey consisted of a computer-tabulated, 21-page form containing 120 questions. Following an introductory page that emphasized anonymity and confidentiality, 49 ques-

From the Veterans Administration Hospital, Miami, Fla. and the University of Michigan Medical Center, Ann Arbor, Mich.

Jorge I. Casariego, M.D.: Director, Crisis Intervention Program, Veterans Administration Hospital, Miami, and Clinical Instructor of Psychiatry, University of Miami School of Medicine, Miami, Fla. John F. Greden, M.D.: Associate Professor of Psychiatry, University of Michigan Medical Center, Ann Arbor, Mich.

Address reprint requests to Jorge I. Casariego, M.D., Director, Crisis Intervention Program (116.A8), Veterans Administration Hospital, 1201 N.W. 16th Street, Miami, Fla. 33125.

(C) 1978 by Grune \& Stratton Inc. 0010-440X/78/1903-0007\$01.00/0 
tions assessed demographic characteristics, educational background, the resident's primary orientation towards psychiatry, personal experience in psychotherapy, experience with various treatments during residency, and plans for future practice of psychiatry. A second part of the survey contained 13 questions on current psychiatric controversies previously published elsewhere. ${ }^{1 x}$

The final segment of the survey asked the respondent to give his opinion of various treatment modalities for 55 items. The ideal treatments were matched up with three hypothetic clinical conditions: schizophrenia, depressive neurosis, and hysterical personality. These conditions were arbitrarily selected as representative of the spectrum of psychiatric entities.

For each of the diagnoses listed, the resident was asked to give his opinion of the therapeutic value on a five point scale, ranging from "contraindicated or absolutely no value" to "minimal value," "moderate value," or "great value." A "no opinion" clause was also available. On the survey, therapeutic value was operationally defined as "the treatment's potential for relieving symptoms and reducing psychopathology." The respondents were asked to assess each modality as if it were the principal treatment, rather than part of a combination therapy. Twenty-five treatment modalities were assessed, some for each of the clinical conditions, and some used more specifically.

The questionnaire was disseminated and collected during the months of May and June, 1973. This was near the end of the academic year in all of the institutions included in this study. The programs surveyed, the number of residents within each program, and the percent responding to this survey were as follows:

(1) Sheppard and Enoch Pratt Hospital, Towson, Md., $N=17(65 \%)$

(2) Bethesda Naval Hospital, Bethesda, Md., $N=8(100 \%)$

(3) Georgetown University Hospital, Washington, D.C., $N=24(63 \%)$

(4) Walter Reed Army Medical Center, Washington, D.C., $N=26(96 \%)$

(5) Freedman's Hospital-Howard University College of Medicine, Washington, D.C., $N=4(67 \%)$

(6) George Washington Medical Center, Washington, D.C., $N=7(88 \%)$

Of the 112 psychiatry residents actually enrolled in six programs at the time of the survey, 86 of

Table 1. Percentage Breakdown of Residents Rating Treatments as Valuable* in Patients With Schizophrenia

\begin{tabular}{|c|c|c|c|c|}
\hline \multirow[b]{2}{*}{ Treatment Modality } & \multicolumn{3}{|c|}{ Year of Residency } & \multirow[b]{2}{*}{$\begin{array}{c}\text { Total } \\
(N=86)\end{array}$} \\
\hline & $\begin{array}{c}\text { First } \\
(N=26)\end{array}$ & $\begin{array}{l}\text { Second } \\
(N=31)\end{array}$ & $\begin{array}{c}\text { Third } \\
(N=29)\end{array}$ & \\
\hline Major tranquilizers & 96 & 96 & 100 & 97 \\
\hline Hospitalization & 96 & 94 & 96 & 95 \\
\hline Family therapy & 89 & 80 & 89 & 85 \\
\hline Milieu therapy & 88 & 81 & 89 & 85 \\
\hline Group therapy & 81 & 71 & 75 & 75 \\
\hline Brief, supportive therapy & 73 & 71 & 70 & 72 \\
\hline Analytically-oriented, long term psychotherapy & 50 & 48 & 56 & 53 \\
\hline Behavior therapy techniques & 65 & 52 & 43 & 53 \\
\hline Inpatient ECT & 34 & 23 & 32 & 30 \\
\hline Tricyclic antidepressants & 12 & 23 & 29 & 22 \\
\hline Lithium carbonate & 4 & 10 & 15 & 10 \\
\hline Outpatient ECT & 4 & 16 & 4 & 8 \\
\hline Encounter groupt & 15 & 0 & 0 & 5 \\
\hline Minor tranquilizers & 8 & 0 & 4 & 4 \\
\hline Hypnotherapy & 8 & 3 & 0 & 4 \\
\hline Psychosurgery & 0 & 0 & 7 & 2 \\
\hline Megavitamins & 0 & 3 & 0 & 1 \\
\hline Amytal/Pentothal interviews & 4 & 0 & $\mathbf{0}$ & 1 \\
\hline Transcendental meditation & 0 & 0 & 4 & 1 \\
\hline Psychomimetics & $\mathbf{0}$ & 0 & 0 & 0 \\
\hline
\end{tabular}

"Respondents answering "Moderate Value" (3) or "Great Value" (4) on a four-point scale.

$\dagger X^{2}$ analysis revealed $p<0.05$. $d f=2$. 
them $(77 \%)$ completed the form. Of these, $30 \%$ were first year residents, $36 \%$ were in their second year, and $34 \%$ were completing their third year of residency. The majority of those we were unable to survey were on vacation or assigned to elective programs in other places. Completion of the questionnaire required approximately $20 \mathrm{~min}$. Questions were answered by one of the investigators (J.I.C) during the administration of the questionnaire. No forms had to be discarded because of inadequate completion. The majority of respondents were enthusiastic, although guarded skepticism about the survey was occasionally observed.

\section{RESULTS}

\section{Attitudes Toward the Value of Treatment Modalities}

In the hypothetic treatment of patients with schizophrenia, the 86 residents were asked to assess the value of 20 therapeutic choices. As illustrated in Table 1, the first line of defense for virtually all respondents in each year of training included major tranquilizers and hospitalization. A second cluster of choices included family, group, and milieu therapies, all rated as being of moderately great value by more than $70 \%$ of residents in each year. More than half of all respondents also felt that analytically-oriented psychotherapy and behavior therapy techniques were valuable in treating patients with schizophrenia. No other modality, including electroconvulsive treatment (ECT) was rated highly by more than one-third of respondents. In fact, it was striking to note the almost complete absence of approval for controversial treatments, such as megavitamins, psychotomimetics, transcendental meditation, and encounter groups. Encounter groups was the only treatment for which the rating was significantly different $\left(\chi^{2}\right.$, $p<0.05$ ) among the year groups.

In the hypothetic treatment of a depressive neurosis, 15 therapeutic modalities were rated. As illustrated in Table $2,85 \%$ of respondents rated analyticallyoriented long-term psychotherapy, brief supportive psychotherapy, and crisis

Table 2. Percentage Breakdown of Residents Rating Treatments as Valuable* in Patients With Depressive Neurosist

\begin{tabular}{|c|c|c|c|c|}
\hline \multirow[b]{2}{*}{ Treatment Modality } & \multicolumn{3}{|c|}{ Year of Residency } & \multirow[b]{2}{*}{$\begin{array}{c}\text { Total } \\
\langle N=86\}\end{array}$} \\
\hline & $\begin{array}{c}\text { First } \\
(N=26)\end{array}$ & $\begin{array}{c}\text { Second } \\
(N=31)\end{array}$ & $\begin{array}{c}\text { Third } \\
\{N=29\}\end{array}$ & \\
\hline Analytically-oriented. long term psychotherapy & 88 & 84 & 82 & 85 \\
\hline Brief, supportive therapy & 88 & 84 & 86 & 85 \\
\hline Crisis intervention & 75 & 81 & 93 & 85 \\
\hline Couple therapy & 92 & 71 & 86 & 82 \\
\hline Family therapy & 80 & 71 & 86 & 79 \\
\hline Tricyclic antidepressants & 85 & 74 & 68 & 75 \\
\hline Hospitalization & 65 & 47 & 57 & 56 \\
\hline Minor tranquilizers & 50 & 29 & 39 & 39 \\
\hline Inpatient ECT & 42 & 33 & 39 & 38 \\
\hline MAO inhibitors & 39 & 32 & 25 & 32 \\
\hline Behavior therapy techniques & 23 & 32 & 28 & 28 \\
\hline Outpatient ECT & 31 & 26 & 14 & 23 \\
\hline Major tranquilizers & 19 & 10 & 18 & 15 \\
\hline Hypnotherapy & 4 & 10 & 4 & 6 \\
\hline CNS stimulants & 4 & 0 & 4 & 2 \\
\hline
\end{tabular}

"Respondents answering "Moderate Value" (3) or "Great Value" (4) on a four-point scale.

† No comparisons among first-, second-, and third-year residents were statistically significant utilizing the $\chi^{2}$ test $\{d f=2)$. 
Table 3. Percentage Breakdown of Residents Rating Treatments as Valuable * in Patients With Hysterical Personality ${ }^{\dagger}$

\begin{tabular}{|c|c|c|c|c|}
\hline \multirow[b]{2}{*}{ Treatment Modality } & \multicolumn{3}{|c|}{ Year of Residency } & \multirow[b]{2}{*}{$\begin{array}{c}\text { Total } \\
(N=86)\end{array}$} \\
\hline & $\begin{array}{c}\text { First } \\
(N=26)\end{array}$ & $\begin{array}{l}\text { Second } \\
(N=31)\end{array}$ & $\begin{array}{c}\text { Third } \\
(N=29)\end{array}$ & \\
\hline Analytically-oriented, long term psychotherapy & 96 & 91 & 92 & 93 \\
\hline Group therapy & 88 & 90 & 89 & 89 \\
\hline Behavior therapy techniques & 38 & 23 & 37 & 32 \\
\hline Psychopharmacologic agents & 15 & 0 & 15 & 10 \\
\hline Hypnotherapy & 16 & 7 & 8 & 10 \\
\hline Amytal/Pentothal interviews & 8 & 0 & 4 & 4 \\
\hline
\end{tabular}

"Respondents answering "Moderate Value" (3) or "Great Value" (4) on a four-point scale.

t No comparisons among first-, second-, and third-year residents were statistically significant utilizing the $\chi^{2}$ test $(d f=2)$.

intervention as being of moderate or great value. Couple therapy and family therapy were rated valuable by $82 \%$ and $79 \%$, respectively. The value of tricyclic antidepressants was supported by $75 \%$ of all residents. Psychobiologic agents, such as minor and major tranquilizers or MAO inhibitors, and inpatient and outpatient ECT received the support of less than $40 \%$ of all the residents. Only $28 \%$ supported behavior therapy techniques, $6 \%$ would use hypnosis, and a mere $2 \%$ would prescribe the much advertised central nervous system stimulants for treating depressive neurosis.

In the treatment of the third clinical condition studied-hysterical personality-six treatment modalities were assessed (Table 3). Ninety-three per cent of all residents considered analytically-oriented long-term psychotherapy to be of significant value in the treatment of this condition. Eighty-nine per cent rated group therapy as being valuable. The remaining four choices were all rated rather low: behavior therapy techniques (32\%), psychopharmacologic agents (10\%), hypotherapy (10\%), and amytal interviews $(4 \%)$.

\section{Effects of Level of Training on Treatment Preferences}

Level of training was noted to be of absolutely no statistical significance in the rating of any treatment modality in any of the three conditions, with one isolated exception. This exception was encounter groups for the treatment of schizophrenia, rated valuable by $15 \%$ of first-year residents; no second- or thirdyear residents approved of it $\left(\chi^{2}, p<0.05\right)$. None of the remaining 24 treatment modalities was rated significantly different by any year group.

\section{Personal Psychotherapy}

We obtained extensive information on a number of demographic characteristics of the surveyed residents, including age, sex, race, marital status, religious heritage, current religious activity, medical education, and involvement in personal psychotherapy before and since the beginning of residency. These characteristics have been extensively reported elsewhere. ${ }^{18}$ An important area of findings relevant to this study is the number of residents who were receiving or had received personal psychotherapy. We found that $28 \%$ of all residents had received therapy prior to residency, and that $35 \%$ had had therapy by their first year, $42 \%$ by their second year, and $52 \%$ by their third year. A total of $43 \%$ of all residents were engaged or had been engaged in psychotherapy at the time of the survey. 


\section{Residents' Psychiatric Orientation, Experience, and Future Career Plans}

When residents were asked to give their self-described psychiatric orientation, $62 \%$ of all residents felt that they were dynamic- or analytically-oriented, $32 \%$ felt that they were eclectic, and only $6 \%$ said they were oriented toward behavioral, biologic-organic, community psychiatry, or other ideology. No significant differences were noted across the year levels for any orientation given. Almost equal numbers of residents rated themselves dynamic-analytically oriented among first-year $(65 \%)$, second-year $(65 \%)$, and third-year $(57 \%)$ groups. Eclectic orientation was second in popularity with $23 \%$ of first-year residents, $32 \%$ of second-year residents, and $43 \%$ of third-year residents. Behavioral, organic, community psychiatry, and "other" were least popular. This category included $11 \%$ of first-year residents, $3 \%$ of second-year residents and no third-year residents. When asked to rate which of the psychiatric orientations were "best taught" in their training programs, a resounding $90 \%$ of all residents rated the dynamicanalytic theory as the one most effectively taught. The remaining $10 \%$ chose one of the others. This attitude clearly carried over to the choices for postresidency practice. For example, a large majority $(57 \%)$ planned to emphasize the dynamic approach after residency, whereas only $33 \%$ would emphasize the eclectic approach and a scant $10 \%$ said they would emphasize behavioral, biologic, or community psychiatry concepts. On the question of their career choices after residency, most residents $(68 \%)$ planned to enter private outpatient practice, $11 \%$ foresaw an academic career, only $7 \%$ said they would practice in a hospital setting, and the remaining $14 \%$ would chose a military career, community psychiatry, private group practice, or other types of practices.

The resident's actual experience with a treatment modality was also assessed (Table 4). Eight arbitrarily selected treatments were rated: the classical analytic format, the analytic couch, ECT, hypnosis, i.v. amytal interviews, behavioral therapy techniques (type not specified), family therapy, and outpatient group therapy. Three treatments were statistically significantly different by year of training. First was outpatient group therapy, which had been utilized by $65 \%$ of all residents. However, only $27 \%$ of first-year residents had ever utilized the treatment as opposed to $81 \%$ and $82 \%$ of second- and third-year residents, respectively. The classical analytic format (defined as 3 or more sessions/week, of explorative-reconstructive psychotherapy) had been used by $31 \%$ of the first-year residents compared to $42 \%$ of second-year residents and $57 \%$ of third-year residents. The third treatment was hypnosis, which $32 \%$ of third-year residents

Table 4. Percentage Breakdown of Residents' Previous Experience With Various Treatment Modalities

\begin{tabular}{|c|c|c|c|c|}
\hline $\begin{array}{l}\text { Treatment Modality } \\
\text { Used at Least Once }\end{array}$ & $\begin{array}{c}\text { First } \\
(N=26)\end{array}$ & $\begin{array}{l}\text { Second } \\
(N=31)\end{array}$ & $\begin{array}{c}\text { Third } \\
(N=29)\end{array}$ & $\begin{array}{c}\text { Total } \\
(N=86)\end{array}$ \\
\hline Classical analytic format ${ }^{*} \dagger$ & 31 & 42 & 57 & 44 \\
\hline Analytic couch & 0 & 0 & 0 & 0 \\
\hline ECT & 42 & 58 & 50 & 51 \\
\hline Hypnosis* & 4 & 13 & 32 & 17 \\
\hline i.v. amytal interview & 31 & 42 & 32 & 35 \\
\hline Behavioral therapy techniques & 27 & 42 & 46 & 39 \\
\hline Family therapy & 39 & 52 & 68 & 53 \\
\hline Outpatient group therapy & 27 & 81 & 82 & 65 \\
\hline
\end{tabular}

e $p<0.05$. df $=2$.

t Defined as three or more sessions per week of explorative-reconstructive psychotherapy. 
had utilized, compared to $13 \%$ and only $4 \%$ of second-and first-year residents, respectively. Interestingly, no resident had ventured to use the "analytic couch."

\section{DISCUSSION}

There were several noteworthy findings in our survey. First was in the area of residents attitudes about the value of treatment modalities. Judging from the responses to this questionnaire, it is evident that all residents had very definite opinions of the value of all the treatment modalities investigated, and that they had no difficulty discriminating sharply among the various treatments examined in the questionnaire. They were able to distinguish among all the 25 modalities when applied to an individual pathologic condition, and also when the modality was used for more than one clinical condition. Possibly the most striking trend we found was the remarkable predilection of the group as a whole for the "individual therapies" and the "social therapies" such as analytically oriented psychotherapy, group therapy, etc. Almost without exception, these therapies were considered highly valuable by all residents in all years. Inversely, the respondents collectively showed a consistent tendency to subtly devalue most somatic treatments regardless of level of training and of clinical condition tested.

In general, modalities like ECT, minor tranquilizers, amytal/pentothal interviews, and psychopharmacologic agents were consistently rated much lower than the nonsomatic therapies. Two exceptions to this trend were the almost universal selection of major tranquilizers and hospitalization as the treatment of choice for schizophrenia and the use of tricyclic antidepressants in the management of depressive neurosis (although this was rated significantly lower than the psychotherapies). The magnitude of the psychotherapeutic predilection is significant even considering the obvious complexities in a questionnaire approach. How can we explain this phenomenon?

Various investigators have tried to classify the ideologic orientation of psychiatrists. Work done in the late 1950 s and early $1960 \mathrm{~s}^{11,19}$ distinguished three main ideologic lines in psychiatry: (1) the directive-organic or somatic, (2) the analyticpsychologic or psychotherapeutic, and (3) the sociotherapeutic. We agree with Armor and Klerman's most recent suggestion that the sociotherapeutic line is really part of a broader psychotherapeutic one. ${ }^{10}$ In fact, our resident's choices tend to support this hypothesis, especially when one considers the clustering of individual psychotherapies and group type therapies near the top of all tables. Using this classification, it is obvious that our resident population showed a strong psychotherapeutic and a weak somatic orientation.

Substantiating evidence of a psychotherapeutic identification was obtained when the residents' self-reported orientation was determined. Sixty-two percent actually labeled themselves as "dynamic/analytic" and $57 \%$ planned to use analytic approaches in their postresidency practice. Furthermore, those who stated they were "eclectic" differed from the analytic group only in greater enthusiasm for behavior therapies, not for other somatic treatments. As stated elsewhere, we feel those residents who labeled themselves eclectic and those calling themselves analytic are all essentially psychotherapeutic in their orientation (nearly $95 \%$ of the residents in this study). ${ }^{18}$

The next major area of findings that warrants comment is the remarkable similarity that we found among the year groups in their ratings of the value of treat- 
ments. No statistically significant preferences were noted for any treatment condition except for the use of encounter groups in the treatment of schizophrenia by first-year residents. This isolated finding, we believe, may actually reflect firstyear residents' genuine ignorance of the psychiatric body of knowledge. Otherwise, the three year groups were basically homogenous in their attitudes toward the value of treatments. From a purely statistical point of view, the findings suggest similarity. However, there were interyear differences noted, especially in the first-year group. First, the 31 first-year residents tended to rate all modalities higher than their second- and third-year counterparts. We believe this may reflect the beginning residents' more genuine enthusiasm and closer adherence to the "medical model" than their more advanced colleagues. Third, the neophytes showed a greater aversion to the analytic and eclectic model.

The answers to questions on demographic characteristics, psychiatric orientations, personal psychotherapy, and actual experience with treatment modalities give us a very interesting body of data. The statistically significant steady progression in the per cent of residents involved in psychotherapy since starting their residency is remarkable indeed. This survey shows that over half of the residents in our population had received some type of personal therapy by the end of their third year. We believe it is possible that the preference shown by these 86 residents for all types of psychotherapy can be explained by the residents' personal experience with therapy. However, we feel that various factors, including resident program selection, identification with teachers and supervisors, and the long-standing tradition and general emphasis of psychotherapeutic and analytic techniques in the Washington-Baltimore area, are probably more important. Whatever the case, it was evident that these residents showed a deep respect for the dynamic theories regardless of level of training. Not surprisingly, we see that the overwhelming trend of our population was toward a career in the private practice of outpatient psychiatry with a strong emphasis on the analytic approaches.

It is noteworthy how early this ideologic parochialism develops. Although we suspected it, the findings did indeed confirm our suspicions. As noted, first-year residents soundly agree with their second- and third-year counterparts in the choice of ideology and in their ratings of treatments. No blanks were seen on the question of self-rated ideology. Whether stemming from anxiety inherent to the current psychiatric training scene, from the perils of "overchoice," from identification with faculty, or perhaps from the resident's own ideologic set predating residency, it seems that the resident is pressured to choose sides early in his training. All residents committed themselves to a distinct theoretic framework quite early. By the end of the first year all residents knew what their orientation to psychiatry was and presumably would be for the rest of their professional lives!

A relevant question for psychiatric educators is whether early identification with any ideology is really desirable. By espousing a rigid theoretic framework in the first year of residency, a resident undoubtedly hinders the accumulation of knowledge and experience with other treatments outside his conceptual framework. Our findings tend to support this hypothesis, as we note that the majority of the residents had never used amytal interview, hypnosis, behavior techniques, or ECT even after three years of training. Obviously, these trends may be confined exclusively to the Washington-Baltimore area and would need validation in other 
areas of the country before generalizations can be made. However, if our findings are in any way representative, it would appear that premature ideologic closure is indeed taking place to a significant degree. It certainly appears so judging by our residents' self-described orientation, and to a lesser degree by their strong preference for the psychotherapies in general.

\section{REFERENCES}

1. Zilborg G, quoted in Merklin L, Little R: Beginning psychiatry training syndrome. Am J Psychiatry 124:193-197, 1967

2. Sharaf MR, Levinson DJ: The quest for omnipotence in professional training. Psychiatry 27:135-149, 1964

3. Fleckles CS: The making of a psychiatrist: The resident's view of the process of his professional development. Am J Psychiatry 128:1111-1115, 1972

4. Holt R: Personality growth in psychiatric residents. Arch Neurol Psychiatry 81:203-215, 1959

5. Holt RR, Luborsky L: Personality Patterns of Psychiatrists, New York, Basic Books, 1958

6. Pasnau RO, Bayley SJ: Personality change in the first year of psychiatric residency training. Am J Psychiatry 128:79-83, 1971

7. Tischler GL: The transition into residency. Am J Psychiatry 128: 1 103-1 107, 1972

8. Scanlan JM: Physician to student: The crisis of psychiatric residency training. Am J Psychiatry 128:1107-1111, 1972

9. Yager J: A survival guide for psychiatric residents. Arch Gen Psychiatry 30:474-479, 1971

10. Armor DJ, Klerman GL: Psychiatric treatment orientation and professional idology. $J$ Health Soc Behav 9:243-255, 1968

11. Sharaf MR, Levinson DJ: Patterns of ideology and professional role-definition among psychiatric residents, in Greenblatt $M$, Levinson DJ, William RH (eds): The Patient and the
Mental Hospital. Glencoe, Ill., Free Press, 1957, pp 263-285.

12. Fried FE, Doherty EG, Coyne L: Psychiatric residents: A survey of training needs, satisfactions and social attitudes. Am J Psychiatry 130;1342-1345, 1973

13. Kurtz R, Kaplan M: Resident attitude development and the ideologic commitment of the staff of psychiatric training. J Med Educ 43:925-930, 1968

14. Myers JM, Rosen HB: Psychiatrists' current attitudes about psychiatric treatment. Compr Psychiatry 7:232-239, 1966

15. Myers JM: Psychiatrists evaluate treatment: 1961-1972. Paper presented at the 126th Annual Meeting of the American Psychiatric Association, Honolulu, Hawaii, 1973

16. Stone WN, Stein LS, Green BL: Faculty and resident commitment to varieties of psychiatric treatment. Arch Gen Psychiatry 24:468-473, 1971

17. Gurel L (ed): A Descriptive Directory of Psychiatric Training Programs in the United States, 1972-1973 (ed 4). Washington, D.C., American Psychiatric Association, 1973

18. Greden JF, Casariego JI: Controversies in psychiatric education: A survey of resident's attitudes. Am J Psychiatry 132:270-274, 1975

19. Ehrlich D, Sabshin M: Chap 4, in Strauss et al: Psychiatric Ideologies and Institutions. New York, Free Press, 1964 